\title{
Methods of automatic vegetation encroachment detection for high voltage power lines
}

K. Sikorska-Łukasiewicz

K. Sikorska-Łukasiewicz, "Methods of automatic vegetation encroachment detection for high voltage power lines," Proc. SPIE 11442, Radioelectronic Systems Conference 2019, 114421G (11 February 2020); doi: $10.1117 / 12.2565756$

SPIE. Event: Radioelectronic Systems Conference 2019, 2019, Jachranka, Poland 


\title{
Methods of automatic vegetation encroachment detection for high voltage power lines
}

\author{
K. Sikorska-Łukasiewicz \\ Radioelectronics Institute, Dept. of Electronics, Military University of Technology, 00-908 Warsaw, \\ gen. Sylwestra Kaliskiego 2
}

\begin{abstract}
Overhead inspections of high voltage power lines are very expensive undertaking. Power lines require systematic inspections to avoid failures and power outages. In each growing season vegetation encroachment is one of the most severe threat. Presently overhead inspections use helicopters and are carried out manually at least once a year. More cost effective systems, using UAV, are being researched. In this paper selected methods from all studied solutions were compared. A cost effective system was proposed using consumer grade UAV with standard camera and deep neural networks for detecting vegetation encroachment.
\end{abstract}

Keywords: Power Line Corridor Monitoring, Vegetation Management, Unmanned Aerial System (UAS), Visual Inspection, Power Line Detection, Tree Crown Segmentation, Tree Species Classification

\section{INTRODUCTION}

Vegetation encroachment near high voltage power lines poses a risk of power failures. Trees falling on or growing into transmission lines can cause power outages or start a fire in the surrounding vegetation. Some sources claim that there should be at least 1,5 meter vegetation free space surrounding transmission lines.

There are multiple strategies for managing vegetation encroachment in high voltage power lines corridors. Removing all vegetation in close proximity to transmission lines is viable only short-term. More viable strategy splits vegetation into desirable and undesirable species. Undesirable species grow fast and reach more than 4 meters. Desirable species do not threaten transmission lines and hinder growth of undesirable species. Such method requires not only vegetation detection but also species recognition.

Information on vegetation in vicinity is mainly collected using aerial data acquisition tools. There are a series of studies researching the possibility of using satellite imagery. [2]

High voltage power line inspection is mainly carries out manually using helicopter. There are many studies researching inspections carried out by unmanned aerial vehicles (UAV) equipped with LIDAR. $[1,11]$ Such system can generate surface model regardless of lighting conditions. LIDAR is a sensor mounted on larger UAV platforms which significantly increases the cost of such a solution. In view of the above there are a series of studies researching systems using visible and near-infrared cameras. Those were the main focus for the purposes of this article.

There are also other solutions such as testing interference of wireless network between successive poles [9] or examination of visual image changes in the area between successive poles [4]. Such solutions require mounting additional measuring devices on every high voltage power line pole.

\section{METHODS OF AUTOMATIC VEGETATION DETECTION}

\subsection{Selected methods}

Problem of power line inspection applies to every country, researching cannot be done freely. Conducting research requires obtaining approval of the infrastructure owner for line inspection. Some researchers use satellite [2] or aerial [3, $5,7]$ imagery taken from high altitude with use of gliders. These methods give results in the form of imagery from a bird's eye view (angle of observation $90^{\circ}$ ). A range of information is not accessible when images are taken from high altitude but is available when images are taken from the level of transmission lines or below. Imagery taken from high altitude also gives limited possibilities to asses technical conditions of power lines.

Radioelectronic Systems Conference 2019, edited by Piotr Kaniewski, Jan Matuszewski, Proc. of SPIE Vol. 11442, 114421G · C 2020 SPIE · CCC code: 0277-786X/20/\$21 · doi: 10.1117/12.2565756 
Table 1. Comparison of selected solutions.

\begin{tabular}{|c|c|c|c|c|c|c|c|}
\hline source & [10] & [3] & [5] & [1] & [2] & [8] & [7] \\
\hline $\begin{array}{c}\text { method of } \\
\text { obtaining } \\
\text { data }\end{array}$ & aerial & aerial & aerial & satellite & satellite & aerial & aerial \\
\hline $\begin{array}{c}\text { angle of } \\
\text { observation }\end{array}$ & $b / d$ & 90 & 90 & 30 & 90 & $b / d$ & 90 \\
\hline sensor carrier & $\begin{array}{l}\text { micro UAV } \\
\text { (DJI } \\
\text { Phantom4) }\end{array}$ & $b / d$ & $\begin{array}{l}\text { micro } \\
\text { UAV } \\
(<0,7 \mathrm{~kg})\end{array}$ & $\begin{array}{l}\text { UAV, } \\
\text { Cessna }\end{array}$ & $\begin{array}{l}\text { QuickBird } \\
\text { satellite }\end{array}$ & $\begin{array}{c}\text { micro } \\
\text { UAV } \\
\text { (DJI } \\
\text { Phantom3) } \\
\end{array}$ & $b / d$ \\
\hline sensor & $\begin{array}{l}\text { video camera } \\
\text { (DJI camera) }\end{array}$ & $b / d$ & $\begin{array}{c}\text { RGB } \\
\text { camera } \\
\text { (consumer } \\
\text { grade) }\end{array}$ & $\begin{array}{c}\text { LIDAR, } \\
\text { multi- } \\
\text { spectral } \\
\text { camera, } \\
\text { RGB } \\
\text { camera } \\
\end{array}$ & $\begin{array}{l}\text { panchroma } \\
\text { tic imaging }\end{array}$ & $\begin{array}{c}\text { RGB } \\
\text { camera } \\
\text { from UAV }\end{array}$ & $\begin{array}{l}\text { RGB camera } \\
\text { (12 MP) }\end{array}$ \\
\hline terrain model & ArcGIS & $b / d$ & CHM & $\begin{array}{c}\text { statistical } \\
\text { analysis of } \\
\text { LIDAR } \\
\text { intensity } \\
\text { data }\end{array}$ & $\begin{array}{l}\text { depth map } \\
\text { generation }\end{array}$ & CHM, SfM & $\begin{array}{c}\text { DEM, } \\
\text { DSM, CHM }\end{array}$ \\
\hline $\begin{array}{c}\text { tree } \\
\text { segmentation }\end{array}$ & $\begin{array}{l}\text { eCognition } \\
\text { Developer, } \\
\text { Multi- } \\
\text { Resolution } \\
\text { Segmentation }\end{array}$ & SIFT & $\begin{array}{l}\text { local } \\
\text { maximum } \\
\text { filter }\end{array}$ & $\begin{array}{l}\text { manual } \\
\text { segmentati } \\
\text { on of tree } \\
\text { crown } \\
\text { texture }\end{array}$ & --- & $\begin{array}{c}\text { local } \\
\text { maxima } \\
\text { detection }\end{array}$ & $\begin{array}{l}\text { eCognition, } \\
\text { color } \\
\text { thresholding, } \\
\text { NPV local } \\
\text { max. }\end{array}$ \\
\hline $\begin{array}{c}\text { tree } \\
\text { classification }\end{array}$ & $\begin{array}{l}7 \text { classes, } \\
\text { manually } \\
\text { exported }\end{array}$ & $\begin{array}{c}1 \\
\text { class }\end{array}$ & --- & 3 classes & --- & --- & 4 classes \\
\hline $\begin{array}{l}\text { method of } \\
\text { automatic } \\
\text { classification }\end{array}$ & GoogLeNet & ELM & --- & $\begin{array}{l}\text { RBF- } \\
\text { kernel, } \\
\text { SVM }\end{array}$ & --- & --- & $\begin{array}{c}\text { contextual } \\
\text { features - } \\
\text { field, shape, } \\
\text { area, height }\end{array}$ \\
\hline $\begin{array}{l}\text { declared } \\
\text { accuracy }\end{array}$ & $88 \%$ & $b / d$ & $b / d$ & $b / d$ & $b / d$ & $b / d$ & $95 \%$ \\
\hline comments & & & $\begin{array}{l}\text { tree height } \\
\text { estimation } \\
\text { from } \\
\text { ortho- } \\
\text { photomap }\end{array}$ & & $\begin{array}{l}\text { tree height } \\
\text { estimation }\end{array}$ & $\begin{array}{c}\text { ground } \\
\text { control } \\
\text { points , } \\
\text { GPS } \\
\text { positioning }\end{array}$ & $\begin{array}{l}\text { detecting } \\
\text { trees with } \\
\text { minimal } \\
\text { crown area } \\
\text { of } 4 \mathrm{~m}^{2}\end{array}$ \\
\hline
\end{tabular}

Legend: CHM (canopy height model), SfM (structure from motion), DEM (digital elevation model), DSM (digital surface model), ELM (extreme learning machine). 
Application of such viewing angle along with LIDAR gives accurate spatial model of the observed area. Using standard camera raise an issue of object height estimation made with stereo vision $[2,5,7]$ or markers located in the observed area [8].

Imagery taken from bird's eye view with angle of observation $30^{\circ}$ are shown in [8]. Very interesting results are achieved using measurements from three independent sensors (LIDAR, multispectral camera, RGB camera) mounted on plane and UAV. In the absence of studies of short distance observations with zero angle of observations, in this paper it is proposed to start researching the possibilities of detecting vegetation using only RGB imagery and applications of machine learning methods.

\subsection{Vegetation detection}

Advances in automated data processing methods takes place in the field of deep learning. In the cited papers there are also systems using neural networks. In [1] manually segmented tree corn textures are used in support-vector machine (SVM) using radial basis function kernel (RBF). Objective of [6] is proposing a method of aiding specialist in detecting single trees in the rainforest imagery taken from RGB camera mounted on UAV. The characteristics that allows to separate tree crowns with human's eye has been described. Based on this a tree crown lighting model with noise affecting it were described. To reduce leaf level noise standard gauss convolution is used. Images are segmented using watershed method. Convolutional neural network may be used for both segmentation and classification.

In this paper U-Net convolutional network is used. This kind of neural network was originally used for medical imagery segmentation. Such images hold many similarities to leaf collection type objects, which is a tree type object that may not keep proper shape in the vicinity of other vegetation. U-Net network effectiveness has been tested for many applications, such as satellite imagery [12], hand [17] or retina vessel segmentation [18].

U-Net architecture in its first half consists of a series of layers with decreasing width (Picture 1). This allows to determine the context in the image. Second half of the U-Net network consists of a series of layers with increasing width allowing positioning of information [13]. Such network architecture is able to achieve good segmentation accuracy even for a small amount of input images. In U-Net [13] network must be forced to learn to separate segmentation areas between different classes. A loss weight map computed using morphological operations is used.

Data for research was collected using $12 \mathrm{MP}$ resolution camera (mounted on a micro UAV weighting under 300 gram) and $16 \mathrm{MP}$ resolution sports camera. Data was collected at a height of $2-3$ meters above the ground. Every taken image contained vegetation with parts of high voltage power lines infrastructure. Training data was manually labelled. According to [13] U-Net architecture can achieve good performance even with relatively small data sets (as small as dozens of samples). As a result of conducted tests it was shown that, using 50 training images is enough for all 15 testing images (not presented to the network previously) to contain correctly segmented vegetation. Sample testing images and segmentation results were shown on Picture 2 and Picture 3. Detected area does not cover vegetation entirely as shown by presented results. This issue will be alleviated significantly by analyzing next frame with partial shift. Each consecutive frame may yield varying perspective of the same vegetation, making previously hard to spot parts, more easily detectable.

One of the methods for measuring similarity between sample sets is Jaccard index, also known as intersection over union. Jaccard index can also be used to measure accuracy of image segmentation. In this scenario it gives ratio of detected area and ground truth overlap to their union. It can be expressed as:

$$
\mathrm{J}(\mathrm{A}, \mathrm{B})=|\mathrm{A} \cap \mathrm{B}| /|\mathrm{A} \cup \mathrm{B}|
$$

In case of testing set average Jaccard index for image was 0.81 . Trained network had issue detecting not only vegetation but also part of the poles themselves. This had the biggest impact on segmentation error and can be alleviated by better preparing training images or preprocessing during classification $[14,15,16]$. 




Figure 1. U-Net architecture [13].
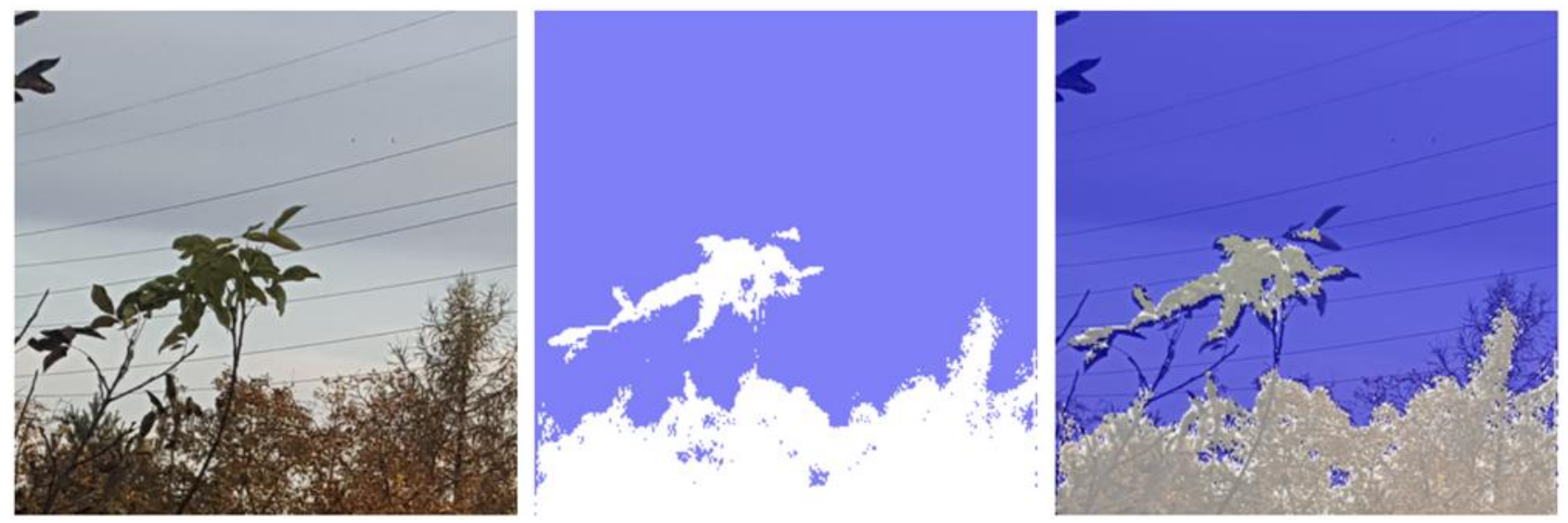

Figure 2. $\mathrm{a}$ - input image, $\mathrm{b}$ - detected vegetation area, $\mathrm{c}$ - comparison of input image and its segmentation. 

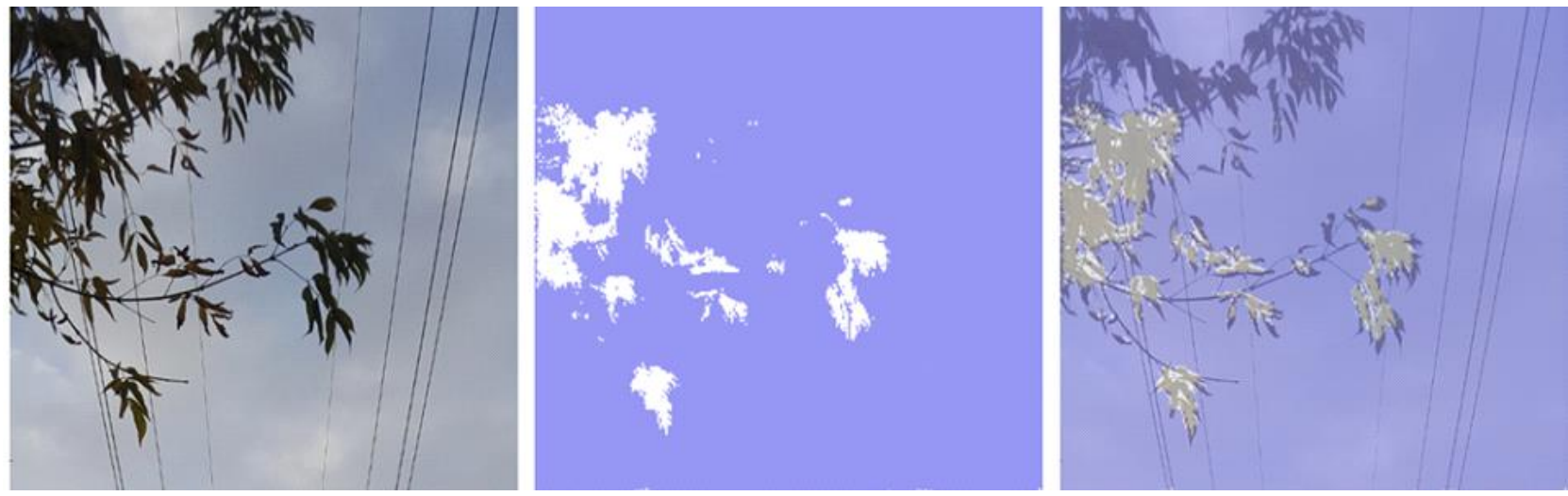

Figure 3. $\mathrm{a}$ - input image, $\mathrm{b}$ - detected vegetation area, $\mathrm{c}$ - comparison of input image and its segmentation.

Lighting conditions are important when collecting data. Data was collected during both cloudy and sunny days to diversify features of the learning set. Data was collected in summer-autumn months (July-September) that provided a diverse color of leaves.

\section{SUMMARY}

Recent developments in the field of UAV and imaging sensors makes UAV a promising platform. Good sensor quality opens the field for advanced data processing. Estimating distance to tree and detecting tree presence in prohibited area using standard UAV sensors is cheaper and faster than using photogrammetry and LIDAR. In case of vegetation monitoring this may lead to more frequent inspections and lower costs.

Distance to classification target and angle of observation have great impact on problem difficulty. Tree type object is easier classified using bird's eye view imagery with full tree crown sight than using side view of an object. Despite the difficulties estimated effectiveness of method proposed in this paper is satisfactory. Methods presented [7, 10] achieve similar estimated effectiveness but with simplified classification conditions.

Collecting data with high resolution in close proximity of inspected infrastructure allows more accurate classification and more precise segmentation of tree crowns particular branches.

\section{REFERENCES}

[1] Li Z., Walker R., Hayward R. F., Mejias L.: "Advances in vegetation management for power line corridor monitoring using aerial remote sensing techniques", 1st International Conference on Applied Robotics for the Power Industry, Montréal, Canada, 2010, DOI:10.1109/CARPI.20105624431.

[2] Qayyum A., Malik A. S., Naufal M., Saad M., Iqbal M., Ahmad R. F., Ab Rashid Bin Tuan Abdullah T., Ramli A. Q.: "Monitoring of Vegetation Near Power Lines Based on Dynamic Programming using Satellite Stereo Images", Kuala Lumpur, 2014, DOI: 10.1109/ICSIMA.2014.7047429.

[3] Malek S., Bazi Y., Alajlan N., AlHichri H., Melgani F.; "Efficient Framework for Palm Tree Detection in UAV Images", IEEE Journal of Selected Topics in Applied Earth Observations and Remote Sensing, 2014, DOI: 10.1109/JSTARS.2014.2331425.

[4] Ahmad J., Malik A. S., Abdullah M. F., Kamel N., Xia L.: "A novel method for vegetation encroachment monitoring of transmission lines using a single 2D camera", Pattern Analysis and Application, 18(2), 2015, DOI:10.1007/s10044-014-0391-9.

[5] Birdal A.l C., Avdan U., Türk T., "Estimating tree heights with images from an unmanned aerial vehicle", Geomatics, Natural Hazards and Risk, 8:2, 2017, DOI: 10.1080/19475705.2017.1300608.

[6] Leo E.: "Individual Tree Crown detection in UAV remote sensed rainforest RGB images through Mathematical Morphology”, Univerity of Amsterdam, 2017. 
[7] Baena S., Moat J., Whaley O., Boyd D. S.: "Identifying species from the air: UAVs and the very high resolution challenge for plant conservation", 2017, DOI:10.1371/journal.pone.0188714.

[8] Mohan M., Silva C. A., Klauberg C., Jat P., Catts G., Cardil A., Hudak A. T., Dia M.: "Individual Tree Detection from Unmanned Aerial Vehicle (UAV) Derived Canopy Height Model in an Open Canopy Mixed Conifer Forest", Forests, 8, 2017, DOI:10.3390/f8090340.

[9] Carvalho F. B. S., Medeiros T. I. O., Rodriguez Y. P. M.: "Monitoring System for Vegetation Encroachment Detection in Power Lines Based on Wireless Sensor Networks", 2018, DOI: 10.1109/TSP.2018.8441408.

[10] Onishi M., Ise T.: "Automatic classification of trees using a UAV onboard camera and deep learning", 2018, arXiv:1804.10390, CoRR abs/1804.10390.

[11] Kurinsky B., Hung M.: "Identification and Visualization of Vegetation Encroachments along Power Line Corridors using LiDAR", International Journal of Research in Geography (IJRG), Volume 1, Issue 1, 2015.

[12] Chhor G., Aramburu C. B., Bougdal-Lambert I.: "Satellite Image Segmentation for Building Detectionusing U-net", 2017.

[13] Ronneberger O., Fischer P., Brox T.: "U-Net: Convolutional Networks for BiomedicalImage Segmentation", 2015, DOI:10.1007/978-3-319-24574-4_28.

[14] Pietrow D., Matuszewski J.: "Objects Detection and Recognition System Using Artificial Neural Networks and Drones”, 2017 Signal Processing Symposium, SPSSympo, Jachranka, 12-14.09.2017, Poland, art. no. 8053689, pp. 1-5. DOI: 10.1109/SPS.2017.8053689.

[15] Matuszewski J.: "Radar signal identification using a neural network and pattern recognition methods", $14^{\text {th }}$ International Conference on Modern Problems of Radio Engineering, Telecommunications and Computer Science, TCSET 2018 - Proceedings, 2018-April, pp. 79-83, Lviv-Slavske, Ukraine, 19-24 Feb. 2018. DOI: 10.1109/TCSET.2018.8336160.

[16] Matuszewski J., Pietrow D.: "Recognition of electromagnetic sources with the use of deep neural networks", XII Conference on Reconnaissance and Electronic Warfare Systems, Proceedings of SPIE - The International Society for Optical Engineering, 110550D (27 March 2019); DOI: 10.1117/12.2524536.

[17] Wang W., Yu K., Hugonot J., Fua P., Salzmann M.: "Recurrent U-Net for Resourve-Constrained Segmentation", The IEEE International Conference on Computer Vision (ICCV), 2019, pp. 2142-2151.

[18] Jin Q., Meng Z., Pham T. D., Chen Q., Wei L., Su R.: "DUNet: A deformable network for retinal vessel segmentation", Knowledge-Based Systems, 178, pp. 149-162. 